\title{
Direct modulation of the outer mitochondrial membrane channel, voltage-dependent anion channel 1 (VDAC1) by cannabidiol: a novel mechanism for cannabinoid-induced cell death
}

\author{
N Rimmerman ${ }^{\star, 1}$, D Ben-Hail' ${ }^{2}$, Z Porat ${ }^{3}$, A Juknat ${ }^{1}$, E Kozela ${ }^{1}$, MP Daniels ${ }^{4}$, PS Connelly ${ }^{4}$, E Leishman ${ }^{5}$, HB Bradshaw ${ }^{5}$, \\ V Shoshan-Barmatz ${ }^{2}$ and $Z$ Vogel $^{1}$
}

Cannabidiol (CBD) is a non-psychoactive plant cannabinoid that inhibits cell proliferation and induces cell death of cancer cells and activated immune cells. It is not an agonist of the classical CB1/CB2 cannabinoid receptors and the mechanism by which it functions is unknown. Here, we studied the effects of CBD on various mitochondrial functions in BV-2 microglial cells. Our findings indicate that CBD treatment leads to a biphasic increase in intracellular calcium levels and to changes in mitochondrial function and morphology leading to cell death. Density gradient fractionation analysis by mass spectrometry and western blotting showed colocalization of CBD with protein markers of mitochondria. Single-channel recordings of the outer-mitochondrial membrane protein, the voltage-dependent anion channel 1 (VDAC1) functioning in cell energy, metabolic homeostasis and apoptosis revealed that CBD markedly decreases channel conductance. Finally, using microscale thermophoresis, we showed a direct interaction between purified fluorescently labeled VDAC1 and CBD. Thus, VDAC1 seems to serve as a novel mitochondrial target for CBD. The inhibition of VDAC1 by CBD may be responsible for the immunosuppressive and anticancer effects of CBD.

Cell Death and Disease (2013) 4, e949; doi:10.1038/cddis.2013.471; published online 5 December 2013

Subject Category: Neuroscience

\section{Introduction}

The non-psychoactive plant cannabinoid, cannabidiol (CBD), in a 1:1 mixture with the psychoactive plant cannabinoid, $\Delta$ 9-tetrahydrocannabinol (THC), has been clinically approved for the treatment of neuropathic pain and spasticity in multiple sclerosis. ${ }^{1}$ CBD alone has strong anti-inflammatory and immunosuppressive effects in diverse animal models of disease such as diabetes, ${ }^{2}$ cancer, ${ }^{3}$ rheumatoid arthritis ${ }^{4}$ and multiple sclerosis. ${ }^{5}$ In addition, CBD has been reported to have anxiolytic, antiemetic and antipsychotic effects. ${ }^{6-8}$ Moreover, CBD has been shown to possess antitumor activity in human breast carcinoma and to effectively reduce primary tumor mass, as well as size and number of lung metastasis in preclinical animal models of breast cancer. ${ }^{3,9} \mathrm{CBD}$ is not an agonist of the classical cannabinoid receptor CB1 and therefore does not induce any of the unwanted psychoactive effects observed with THC. While the molecular targets of $\mathrm{CBD}$ are elusive, these reports incite growing clinical interest in the use of CBD to treat these diseases. ${ }^{10}$
Numerous molecular targets of CBD have been described depending on the experimental models used, among them are the GPCRs: GPR55, GPR18, and 5HT1A receptors (for review, refer to previous studies ${ }^{8,11}$ ). In addition, CBD has been shown to bind to the equilibrative nucleotide transporter affecting the activity of $\mathrm{A} 2 \mathrm{~A}$ adenosine receptors. ${ }^{12} \mathrm{CBD}$ was also shown to activate various transient receptor potential channels (TRPV1, TRPV2, TRPM8, TRPA1;ref. 13), as well as the nuclear peroxisome proliferator-activating receptor $\gamma$ $(\operatorname{PPAR} \gamma){ }^{14}$ Furthermore, Ryan et al. ${ }^{15}$ reported the involvement of a specific mitochondrial target for CBD in hippocampal neurons and glia, the mitochondrial sodiumcalcium exchanger. In these cells CBD was neuroprotective and did not affect cell viability. ${ }^{15,16}$

While CBD was reported as a neuroprotective agent in many in vitro and in vivo models, ${ }^{15,17,18}$ it has been shown to induce cell death in cancer cells and several types of immune cells. In cancer models, CBD induced cell death in breast cancer cells (MDA-MB-231; MCF-7, SK-BR3,

\footnotetext{
${ }^{1}$ The Dr. Miriam and Sheldon G Adelson Center for the Biology of Addictive Diseases, Department of Physiology and Pharmacology, Sackler Faculty of Medicine, Tel Aviv University, Tel Aviv, Israel; ${ }^{2}$ The Department of Life Sciences and the National Institute for Biotechnology in the Negev, Ben-Gurion University of the Negev, Beer-Sheva, Israel; ${ }^{3}$ The Flow Cytometry Unit, Weizmann Institute of Science, Rehovot, Israel; ${ }^{4}$ National Heart Lung and Blood Institute, Bethesda, MD, USA and ${ }^{5}$ The Department of Psychological and Brain Sciences, Indiana University, Bloomington, IN, USA

${ }^{*}$ Corresponding author: N Rimmerman, Miriam and Sheldon G Adelson Center for the Biology of Addictive Diseases, Department of Physiology and Pharmacology, Sackler Faculty of Medicine, Tel Aviv University, Tel Aviv 6997801, Israel. Tel: +972 36405615 or + 9728 9342995; Fax: +972 98345106 ; E-mail: Neta.rimmerman@weizmann.ac.il or Netarimm@post.tau.ac.il

Keywords: cancer; cannabidiol; cell death; microglia; mitochondria; voltage-dependent anion channel 1.

Abbreviations: VDAC1, voltage-dependent anion channel 1; CBD, cannabidiol; PPAR $\gamma$, peroxisome proliferator-activating receptor $\gamma$; TRP, transient receptor potential channels; ROS, reactive oxygen species; OMM, mitochondrial outer membrane; Cys A, cyclosporin A; PTX, pertussis toxin; TBHP, tert-butyl hydroperoxide; MST, microscale thermophoresis; PTP, mitochondrial permeability transition pore

Received 11.7.13; revised 27.10.13; accepted 31.10.13; Edited by D Bano
} 
ZR-75-1) via mitochondria-mediated signaling pathways as characterized by swollen mitochondria, reduced mitochondrial membrane potential, and increased reactive oxygen species (ROS) production. ${ }^{19}$ Additionally, CBD was shown to induce cell death in thymoma cells, leukemic cell lines, and gliomas. ${ }^{17,20-23}$

In immune cells, CBD induced cell death in primary murine thymocytes and splenocytes. ${ }^{23,24}$ In human monocytes CBD has shown mixed effects on cell death depending on time in culture and the anti-oxidative capacity of the cells. ${ }^{25}$ Moreover, CBD has been shown to induce cell death in mouse peritoneal macrophages, ${ }^{26} \mathrm{BV}-2$ microglial cells, ${ }^{27}$ and murine microglial cells. ${ }^{28}$

Using the BV-2 microglial cell model, we reported that CBDinduced cell death can be prevented by the cholesterol chelating/lipid raft disrupting agent methyl- $\beta$-cyclodextrin. ${ }^{27}$ Similar results were reported by $\mathrm{Wu}$ et al. ${ }^{28}$ for murine microglia, supporting the idea that CBD targets analogous molecular mechanisms in BV-2 and primary microglial cells. We have also demonstrated that CBD stimulates the transcription of genes regulating cellular stress responses, induces anti-inflammatory effects (by downregulating the expression of proinflammatory genes and upregulating antiinflammatory mediators) and modulates the transcripts of cholesterol-related enzymes. ${ }^{27,29-33}$

Here we report the identification of a new mitochondrial molecular target for CBD, the voltage-dependent anion channel 1 (VDAC1). VDAC1 is a multifunctional channel located in the mitochondrial outer membrane (OMM). It has a central role in controlling cellular energy and metabolism by mediating the transfer of metabolites between the mitochondria and the cytosol. ${ }^{34}$ Moreover, VDAC1 is a key factor in mitochondria-mediated apoptosis, participating in the release of mitochondrial pro-apoptotic proteins to the cytosol (e.g. cytochrome $c$, apoptosis-inducing factor, Smac/DIABLO), and interacting with apoptosis regulatory proteins (e.g. hexokinase and members of the Bcl-2 family ${ }^{35}$ ). Purified VDAC1 reconstituted into a planar lipid bilayer shows voltagedependent bell-shaped conductance. At low membrane potentials $(-20$ to $+20 \mathrm{mV}$ ) the channel is at its open state and shows high conductance. At higher positive or negative potentials, the channel conductance is reduced, becoming impermeable to large molecules such as ADP and ATP. ${ }^{35}$ In the reduced conductance state, the impaired VDAC1 function can lead to an energetic crisis and compromised cell viability. ${ }^{35}$ Indeed, modulating VDAC1 channel conductance in cancer cells has been proposed as a lead for developing novel anticancer treatments. ${ }^{36}$

This study demonstrates that in BV-2 microglial cells, CBD affects the homeostasis of cytosolic calcium, mitochondrial function and morphology, and cell viability. These effects seem to arise from a direct CBD-induced inhibition of VDAC1 channel conductance. This idea is supported by the following findings: (1) CBD colocalizes with mitochondrial VDAC1-rich membranes (demonstrated using two fractionation methods coupled to mass spectrometry and western blot analysis). (2) CBD strongly reduces the conductance of purified VDAC1 channels reconstituted into artificial membranes, and (3) CBD directly interacts with fluorescently labeled VDAC1 (shown using the microscale thermophoresis method). This direct interaction of CBD with VDAC1 causing inhibition of channel conductance may be responsible for the strong immunosuppressive and anticancer effects of CBD.

\section{Results}

Under serum-free conditions, CBD induced cell death of BV-2 cells as revealed by cell cycle analysis (counts in the subG1). This cell death was highly dependent on CBD concentration (Figure 1a). Cell death was not significantly reversed by the CB2 antagonist SR144528 (SR; Figure 1b). In addition, this effect of CBD was not influenced by pretreatment with pertussis toxin (PTX; Figure 1c), suggesting that it is not acting through a Gi/o coupled GPCR. Furthermore, CBD-induced cell death was not influenced by $\mathrm{N}$-acetylcysteine (NAC) or by the nitric oxide synthase inhibitor L-NAME (Figure 1c).

CBD was previously suggested to act through the nuclear receptor PPAR $\gamma .{ }^{14}$ GW9662, an antagonist of this receptor, was recently reported to reduce CBD-induced lung cancer cell death. $^{37}$ We found that in the BV-2 microglial cell line, GW9662 pretreatment did not reverse the effect of CBD. On the contrary, CBD together with GW9662 enhanced BV-2 cell death (GW; Figure 1b).

Another reported target of CBD is the equilibrative nucleoside transporter 1 affecting the activity at A2A adenosine receptors. ${ }^{12,38}$ Indeed, when cells were pre-treated with the specific adenosine antagonist ZM241385, a slight, yet significant, protective effect was observed (ZM; Figure 1b). CBD-induced cell death was also slightly but significantly reduced by ruthenium red (a general TRPV antagonist, as well as inhibitor of calcium-dependent activities, including VDAC1) and by the serotonin 5HT1A antagonist WAY100635 (RR and WAY; Figure 1c). In line with our report regarding the modulation of transcription of cholesterol-related genes such as sterol-O-acyl transferase and CYP27A1 by $\mathrm{CBD}^{27}$ we found that cholesterol enrichment reduced $C B D$-induced cell death (Figure 1d).

Finally, several groups including McKallip et al. ${ }^{22}$ Ryan et al. ${ }^{15}$ and Mato et al. ${ }^{39}$ reported interactions of CBD with mitochondrial targets as evidenced by its effects on mitochondrial membrane potential, ROS production, and changes in calcium ion homeostasis. We therefore tested the effect of cyclosporin A (Cys A), a blocker of the mitochondrial permeability transition pore (PTP) on CBDinduced cell death. We found that Cys A had a very strong protective effect and almost completely rescued the cells from CBD-induced cell death (Figure 1b).

Next, electron microscopy was used to visualize the cell morphological changes induced by CBD treatment. Cells treated with CBD $(2 \mathrm{~h})$ under serum-free conditions induced severe mitochondrial swelling (Figure 2, upper panels). A similar trend was observed following $6 \mathrm{~h}$ of CBD treatment in the presence of $5 \%$ serum (data not shown). Vehicletreated cells showed normal mitochondrial morphology (Figure 2, lower panels).

The mitochondria are an important calcium hub, affecting cytosolic calcium levels. The effect of CBD treatment on cytosolic calcium levels was analyzed using single-cell calcium imaging. Our recordings revealed a quick transient and dose-dependent increase in intracellular calcium, which 


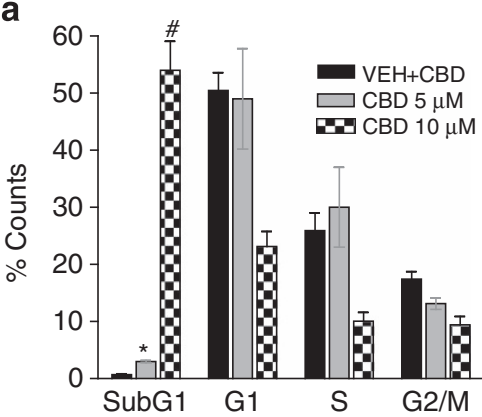

C

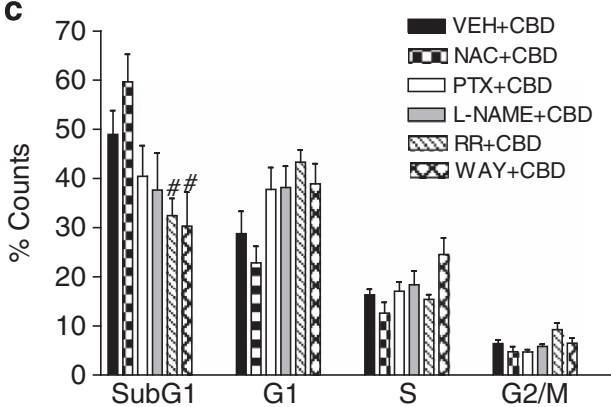

b

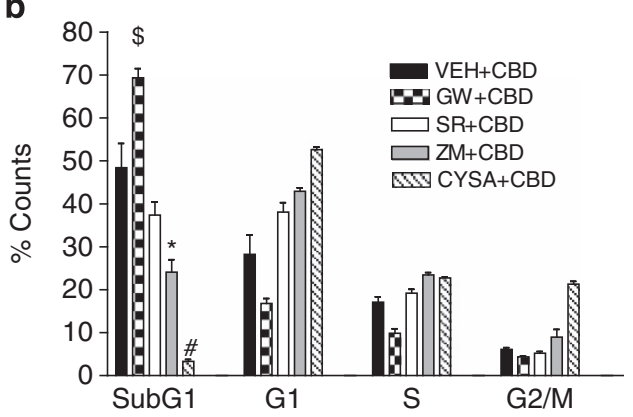

d

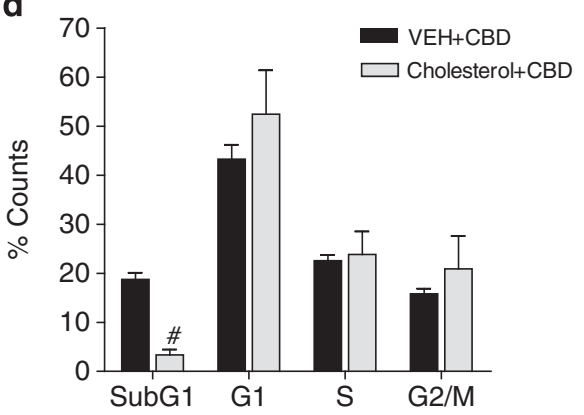

Figure $1 \mathrm{CBD}$ induces cell death of BV-2 microglial cells. (a) CBD dose-dependently induces cell death in BV-2 cells after $2 \mathrm{~h}$ treatment under serum-free conditions. Cell death is quantified as the increase in $\%$ counts in the subG1 phase (100\% = total counts in all cell cycle phases: SubG1, G1, S, and G2/M). Significance of SubG1 counts compared with vehicle (ethanol $0.1 \%$ ). CBD $5 \mu \mathrm{M},{ }^{*} P<0.001, n=3$; CBD $10 \mu \mathrm{M},{ }^{\#} P<0.001 ; n=5$, one-way ANOVA with Bonferroni post hoc). (b) The effect of several antagonists on $\mathrm{CBD}(10 \mu \mathrm{M})$-induced cell death. CBD-induced cell death was significantly enhanced by pretreatment with $7.5 \mu \mathrm{M} \mathrm{GW} 9662\left(\mathrm{GW} ;{ }^{\$} P<0.01, n=3\right.$, one-way ANOVA with LSD post hoc) and was significantly attenuated by $5 \mu \mathrm{M}$ ZM241385 (ZM; ${ }^{*} P<0.002, n=3$, one-way ANOVA with LSD post hoc) and by $7 \mu \mathrm{M}$, Cys A (CYSA; ${ }^{\#} P<0.001, n=4$, one-way ANOVA with LSD post hoc), CBD-induced cell death was not affected by $0.5 \mu$ M SR144528 (SR; $n=6$ ). All antagonists were dissolved in DMSO ( $0.1 \%$ final concentration). (c) $\mathrm{CBD}(10 \mu \mathrm{M})$-induced cell death was significantly reduced by pretreatment with $10 \mu \mathrm{M}$ ruthenium red (RR; ${ }^{*} P<0.05, n=3$, one-way ANOVA with LSD post hoc), $10 \mu \mathrm{M}$ WAY100635 (WAY; ${ }^{\#} P<0.05, n=3$, one-way ANOVA with LSD post hoc). CBD-induced cell death was not affected by $100 \mathrm{ng} / \mathrm{ml}$ PTX ( $n=3$ ), $1 \mathrm{mM} \mathrm{NAC}(n=5)$, or $50 \mu \mathrm{M} \mathrm{L-NAME}(n=3)$. All antagonists were diluted in water (excluding WAY100635 which was diluted in saline). (d) Cholesterol enrichment (50 $\mu \mathrm{M}$, in sesame oil final concentration $0.1 \%)$ significantly reduced CBD $(10 \mu \mathrm{M})$-induced cell death ( ${ }^{\#} P<0.001, n=3-5$, one-way ANOVA with LSD post hoc). All compounds tested didn't induce cell death in the absence of CBD

lasted several minutes (Figures $3 a$ and $b$ ). This calcium increase leveled off and was followed by a delayed large increase in calcium level that coincided with mitochondrial swelling and cell death (Figure 3c). The transient intracellular calcium elevation peak was markedly attenuated by removal of extracellular calcium (Figure $3 b$ ).

Two functional assays were performed in order to assess changes in mitochondrial functions following CBD treatment: (1) changes in mitochondrial membrane potential $(\Delta \psi)$, and (2) changes in ROS production. These assays revealed that CBD treatment dose-dependently decreases mitochondrial membrane potential with an $\mathrm{IC}_{50}$ of $10 \mu \mathrm{M}$ (Figure $4 \mathrm{a}$ ) and induces ROS production with an $\mathrm{EC}_{50}$ of $4.9 \mu \mathrm{M}$ (Figure $4 \mathrm{~b}$ ).

The possibility of CBD transport into the mitochondria has not been previously investigated. Using two cell fractionation methods coupled to mass spectrometry and western blot analysis, we revealed that following cell pretreatment, CBD colocalized with mitochondrial VDAC1-rich membrane fractions (Figures $5 \mathrm{a}-\mathrm{c}$ ). In the first method according to Wiecowski et al. ${ }^{40}$ we separated homogenized BV-2 cells into the following organelles: crude mitochondria, lysosomes/ plasma membrane, ER, and cytosol. Appropriate antibodies against VDAC1, LAMP-1, $\beta$-COP, and $\beta$-actin were used as protein markers for the various cell fractions. We found that CBD was present at the highest level in the crude mitochondrial fraction, rich in VDAC1 (Figures $5 a$ and b). To further verify these results, we used an additional fractionation method, which separates cell membrane fractions on a continuous OptiPrep/sucrose density gradient. This method separates membranes on a density gradient with the lighter fractions colocalizing with markers of lipid rafts. ${ }^{33,41,42} \mathrm{We}$ found that the distribution of the mitochondrial marker VDAC1, and thus of mitochondrial membranes, was very similar to that of CBD. Both were found predominantly in fraction 6 (Figure 5c).

The effects of CBD on mitochondrial morphology and function together with its colocalization with VDAC1-rich membranes led us to hypothesize an interaction between VDAC1 and CBD. To test the physiological interaction of CBD with VDAC1, purified sheep VDAC1 was reconstituted into a planar lipid bilayer and the effect of CBD on its channel conductance was analyzed. Recordings of the current through the channel before and after the addition of CBD revealed a direct and strong inhibition of VDAC1 conductance by CBD. VDAC1 conductance is voltage-dependent, with the highest conductance obtained between -20 and $+20 \mathrm{mV}$, and with decreased conductance at both high negative or positive potentials. At $-10 \mathrm{mV}$, when VDAC1 is at its fully open state, CBD strongly decreased VDAC1 conductance (Figure 6ai). Moreover, at $-60 \mathrm{mV}$ when VDAC1 shows different conducting 

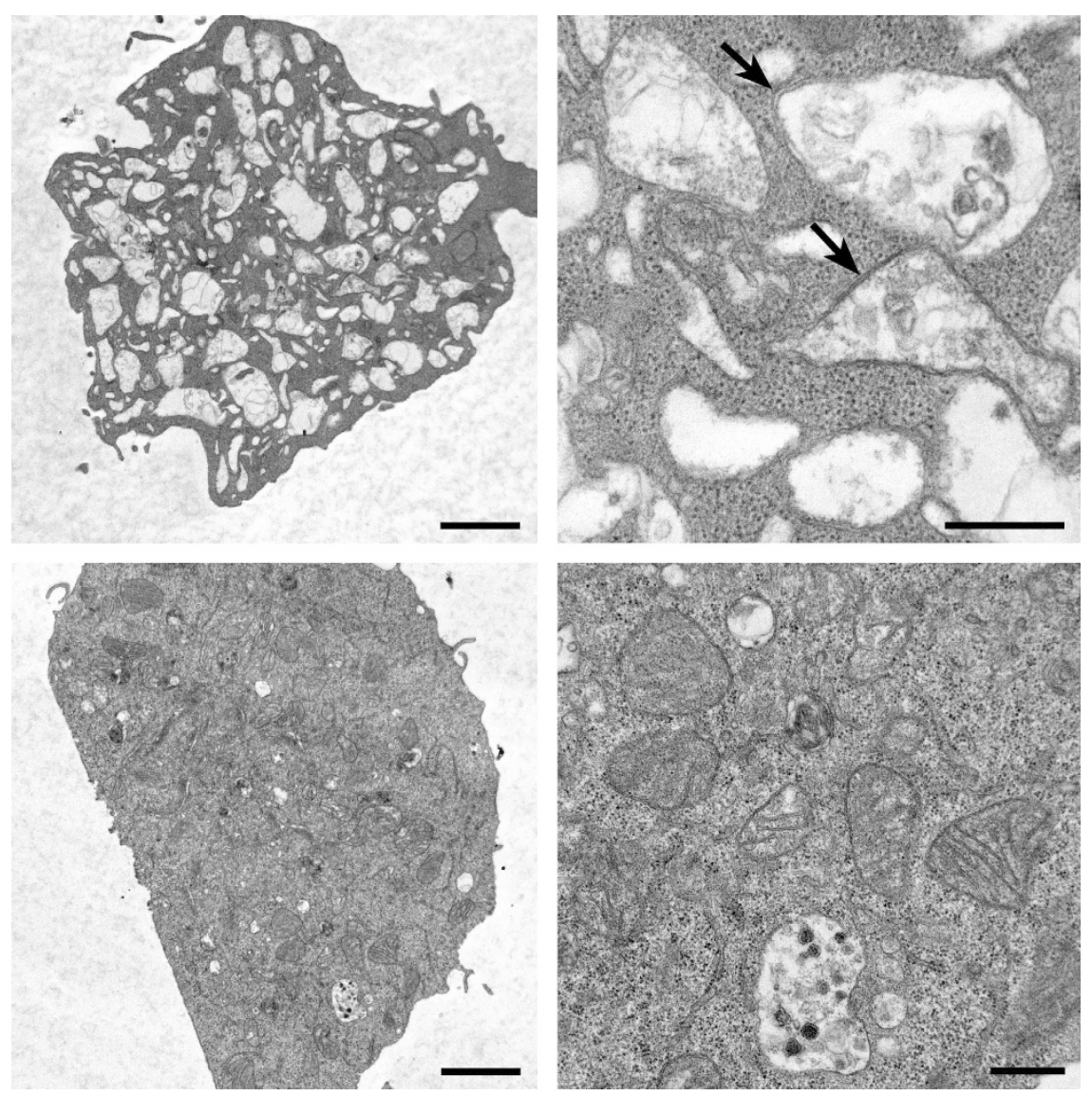

Figure $2 \mathrm{CBD}$ induces mitochondrial swelling. Upper panels: electron micrographs show many swollen mitochondria (large electron lucid structures within the cell) after $2 \mathrm{~h}$ of CBD treatment under serum-free conditions. Arrows in the high magnification panel indicate two swollen mitochondria in which the inner and outer membranes can still be seen. Lower panels: control (vehicle treated) cells show normal density and morphology of mitochondria. The scale bar is $2 \mu \mathrm{m}$ in the low magnification images and $0.5 \mu \mathrm{m}$ in the high magnification images

sub-states, CBD maintained VDAC1 at a low conductance state (Figure 6aii). Overall, in a voltage range between 60 to $-60 \mathrm{mV}, \mathrm{CBD}$ reduced VDAC1 conductance at all applied voltages (Figure $6 b)$. This effect did not depend on the side of CBD addition, the cytosol (cis) side or the intermembrane space (trans) side, suggesting that $\mathrm{CBD}$ can reach the VDAC1-binding site regardless of the membrane side of administration.

In order to test the physical interaction between CBD and purified VDAC1, we used the microscale thermophoresis method. This method records the directed movement of particles in a microscopic temperature gradient and enables quantitative analysis of molecular interactions in solution. The results show that CBD interacted with purified fluorescently labeled rat VDAC1 with a $K_{\mathrm{d}}$ of $11.2 \pm 6 \mu \mathrm{M}$, whereas $N$-arachidonoyl ethanolamine (AEA), an endogenous cannabinoid that was used as a control, showed no interaction with fluorescently labeled VDAC1 (Figure 6c).

\section{Discussion}

The effects of $\mathrm{CBD}$ on microglial cells in vitro and in vivo led us to search for the molecular targets that may be affecting cell function and viability. Using cell cycle analysis, we screened many of the previously reported CBD targets, and identified the involvement of a mitochondrial target. We hypothesized that this target should differ from the previously described mitochondrial sodium-calcium exchanger affected by CBD in neurons and glia. ${ }^{15}$ This is because CBD in these cells has been reported to have neuroprotective effects against mitochondrial toxins and did not affect cell viability. ${ }^{15,16}$ Additionally, the effects of $\mathrm{CBD}$ on calcium regulation in neurons could be reversed by the sodium-calcium exchanger inhibitor, CGP 37157, but not by the PTP antagonist Cys A. Conversely, in BV-2 cells Cys A (but not CGP 37157, data not shown) protected against CBD-induced cell death. These results support the idea of a novel mitochondrial target affecting BV-2 microglial cell viability.

Cys A which was found to be protective against CBD-induced cell death is an inhibitor of the mitochondrial PTP, a large pore of unresolved molecular structure that increases the permeability of the inner mitochondrial membrane ${ }^{43}$ While transient PTP opening may serve the purpose of providing a fast calcium release mechanism, persistent PTP opening is followed by deregulated release of matrix calcium, loss of mitochondrial membrane potential, mitochondrial swelling and rupture of the OMM. ${ }^{35,36,44,45}$ 
a

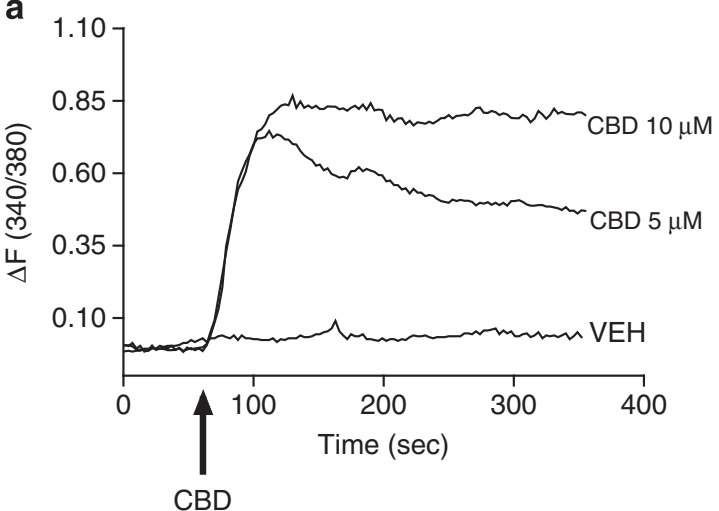

b

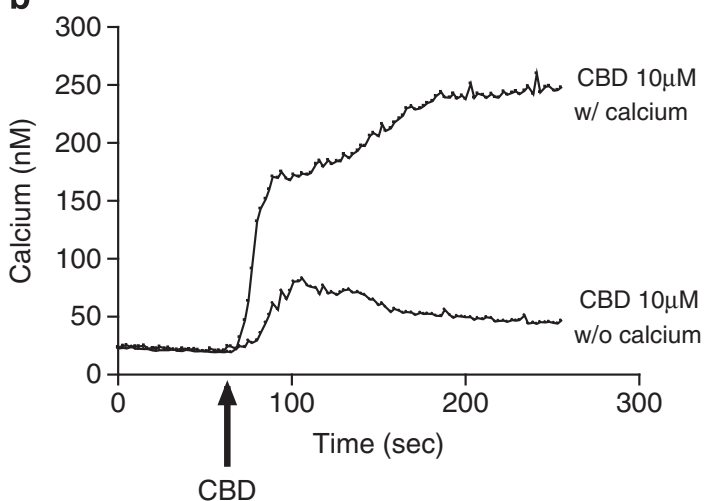

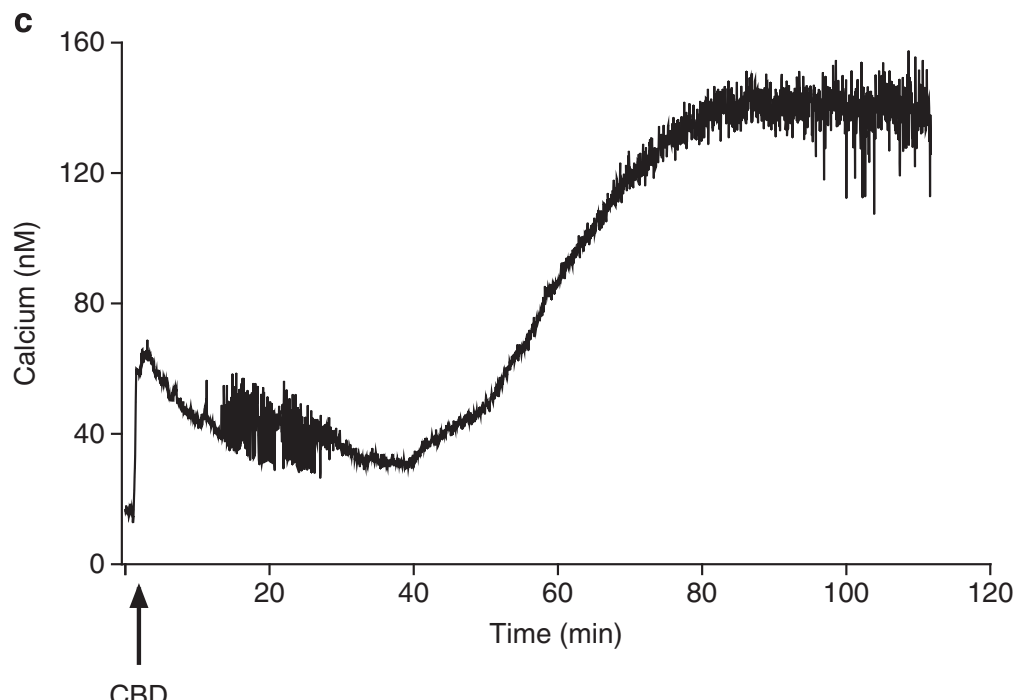

Figure 3 CBD induces intracellular calcium influx in BV-2 cells. (a) CBD dose-dependently induces calcium influx in BV-2 microglial cells under serum-free conditions. The calcium traces are an average of three independent experiments each $(n=15-30$ single cells per experiment). (b) CBD-induced calcium influx is attenuated by the removal of extracellular calcium. The calcium traces are an average of three independent experiments each ( $n=15-30$ single cells per experiment). (c) A representative trace (average of $n=15$ cells) showing the long-term effects of CBD on the intracellular calcium concentration. Treatment with CBD induces a transient intracellular calcium increase, followed by a delayed large calcium increase

Aside from the protective effect of Cys A that points to a cascade involving the PTP, our study supports a specific role for VDAC1 (a proposed constituent of PTP ${ }^{35,45}$ ) in CBDinduced cell death. We show using two fractionation methods that CBD colocalizes with VDAC1-rich mitochondrial membranes. Moreover, using single VDAC1 channel recordings we provide evidence that CBD potently decreases VDAC1 channel conductance, regardless of the side (cis or trans) of CBD addition, suggesting a direct interaction of CBD with VDAC1. This is further supported by our microscale thermophoresis results revealing a direct interaction between CBD and purified VDAC1 with affinity in the range of concentrations producing its cellular effects.

In its open state, VDAC1 is permeable to ions and to uncharged molecules up to $5 \mathrm{kDa}$, thus mediating a flux of ions, nucleotides and other metabolites across the OMM. ${ }^{35}$ VDAC1 closure results in reduced metabolite exchange across the mitochondrial OMM affecting cellular metabolism and cell viability. ${ }^{46,47}$ The interaction between CBD and VDAC1 results in reduced channel conductance and eventually leads to cell death. A similar effect on VDAC1 conductance was reported for several anticancer drugs (for review, refer to previous studies ${ }^{35,36}$ ). This observation may explain the antitumorigenic effects of CBD as reported by several groups. ${ }^{3,9}$

Our cell cycle analysis showed a strong protective effect of cholesterol enrichment on the viability of BV-2 cells. This may be explained by the described interaction of VDAC1 with cholesterol. Specifically, Popp et al. ${ }^{48}$ reported that sterols are essential for proper insertion of VDAC1 into bilayer membranes and that cholesterol increases VDAC1 conductance. Based on this, enriching membranes with cholesterol could potentially counteract the CBDinduced reduction in VDAC1 conductance. Recent studies further support a VDAC1-cholesterol interaction. Hiller et al. ${ }^{49}$ showed that in its 3D structure VDAC1 contains cholesterol molecules that are important for its proper folding. Furthermore, studies using mass spectrometry suggested that VDAC is a necessary component of a protein complex involved in mitochondrial membrane cholesterol distribution, affecting oxidative phosphorylation and induction of apoptosis. ${ }^{50,51}$ 

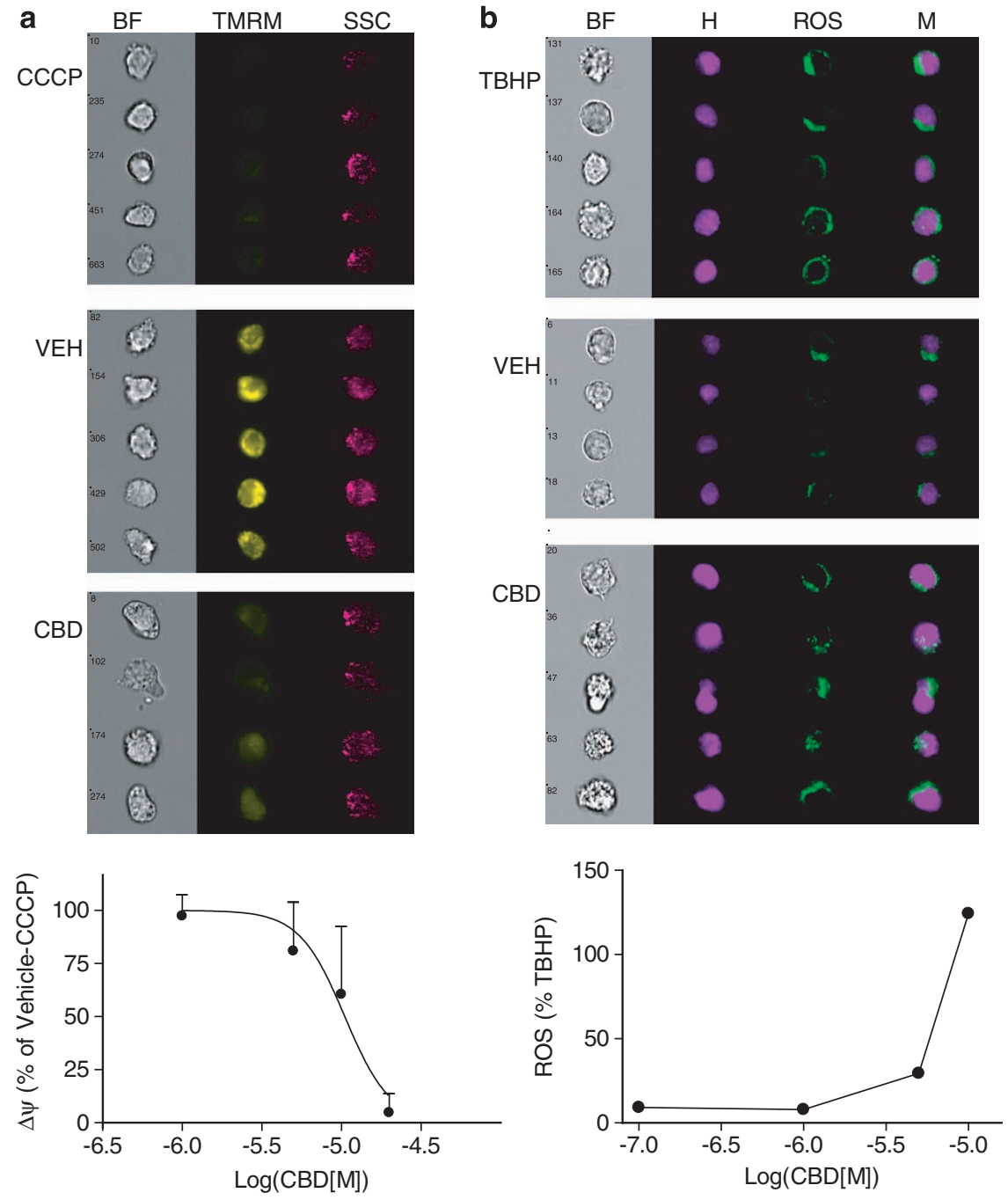

Figure $4 \mathrm{CBD}$ induces loss of mitochondrial membrane potential and increases ROS production. (a) CBD dose-dependently reduces mitochondrial membrane potential $(\Delta \psi)\left(\mathrm{IC}_{50} 10 \mu \mathrm{M}\right)$. Cells were stained with the potentiometric red fluorescent dye TMRM. CCCP $(50 \mu \mathrm{M})$, which causes rapid loss of $\Delta \psi$ potential (loss of TMRM fluorescence) was used as a control for calculating the effect of CBD. The ImageStream images shown here were taken from the distribution mean. The dose-response curve is a representative of three experiments. (b) $C B D$ dose-dependently induces $\mathrm{ROS}$ production ( $\mathrm{EC}_{50} 4.9 \mu \mathrm{M}$ ). Cells were incubated with $\mathrm{CBD}$ at the indicated concentrations, or with $300 \mu \mathrm{M}$ TBHP used as a positive control, followed by staining with carboxy- $\mathrm{H}_{2} \mathrm{DCFDA}$. ImageStream images shown were taken from the distribution mean. The doseresponse curve is a representative of three experiments

Mitochondria serve as a cellular calcium hub regulating cytosolic calcium levels. VDAC1 appears to be the main channel transporting calcium across the OMM and its permeability to calcium is affected by the channel's conductance state. ${ }^{52-54}$ Specifically, in its closed state, which is associated with reduced cell viability, VDAC1 shows increased calcium flux from the cytosol into the mitochondria. ${ }^{54}$ In our cells, CBD induced a quick and transient calcium peak (which was dependent on extracellular calcium) followed by a second prolonged peak resulting in cytosolic calcium overload and cell death. CBD-induced VDAC1 channel closure increases mitochondrial calcium levels, leading to increased mitochondrial permeability, cytosolic calcium overload, loss of mitochondrial membrane potential, increased ROS production, mitochondrial swelling and cell death, a scenario well documented for many cell death inducers. We observed a small protective effect against
CBD-induced cell death by pretreatment with ruthenium red. This is in line with the reported interaction of ruthenium red with VDAC1, ${ }^{52}$ which was shown to protect cells against apoptotic stimuli. ${ }^{55}$ At this point we cannot determine the contribution of each of the ruthenium red molecular targets (TRPV or VDAC1) to the observed changes in cellular viability.

Unfortunately, we were not able to get efficient siRNA silencing of VDAC1 in BV-2 cells, probably due to the inherent difficulty to transfect BV-2 cells with good efficiency. ${ }^{56}$ We therefore performed VDAC1 silencing in the human glioma cell line U-87 previously reported to be susceptible to CBDinduced cell death. ${ }^{57}$ We found that reduction in VDAC1 expression by $70 \%$ reduced the susceptibility of these cells to CBD-induced apoptosis. In scrambled siRNA-treated cells, CBD increased apoptosis by $28 \%$ over vehicle, while in siVDAC1-treated cells CBD increased apoptosis by only $16 \%$ over vehicle, $n=3$ (data not shown). 

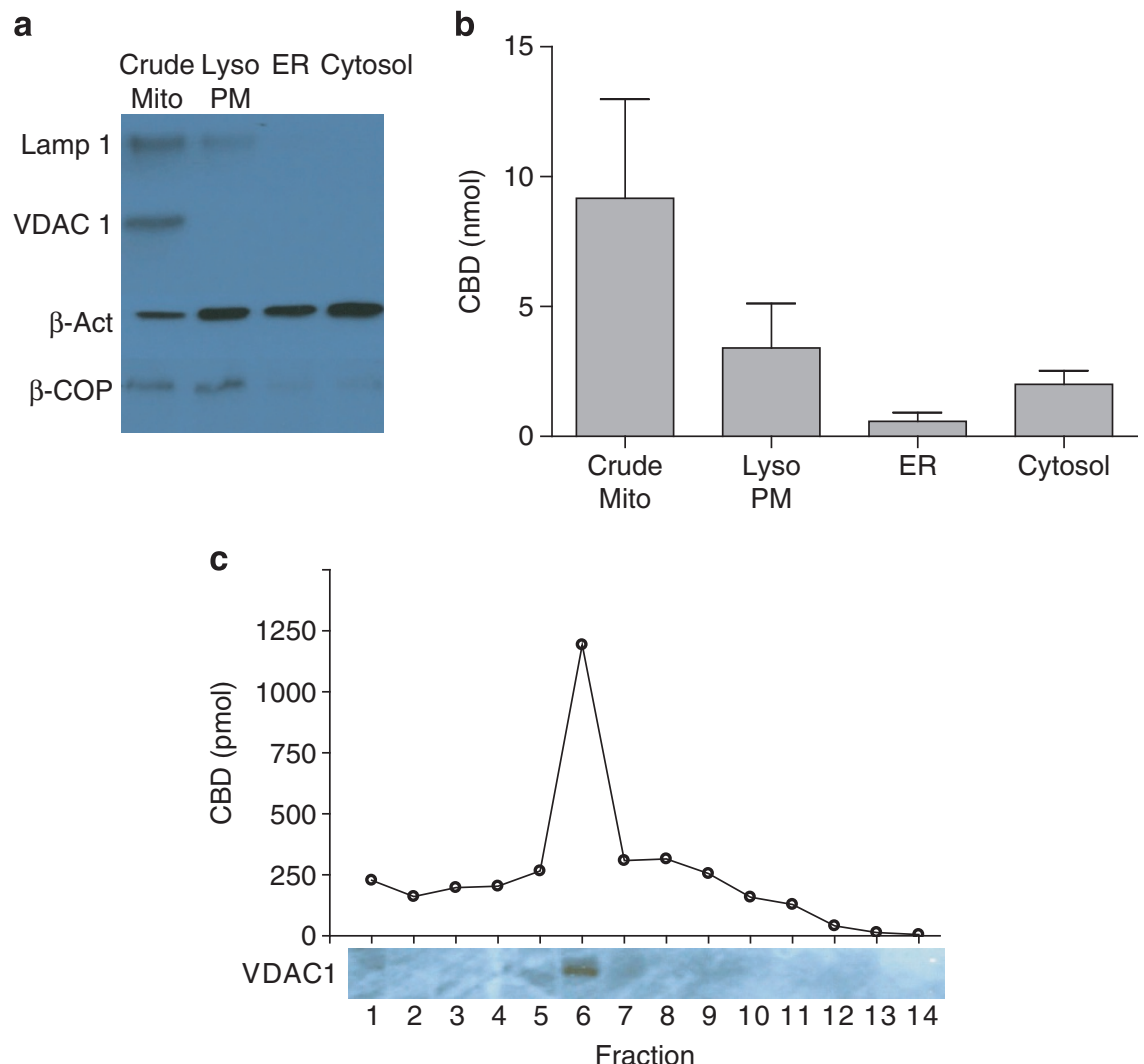

Figure 5 CBD colocalizes with VDAC1-rich mitochondrial membranes (a) Cell organelles were separated into four fractions. An equal amount of protein was loaded per lane. The results are representative of two independent experiments. Protein marker distribution among the following fractions: crude mitochondria (Crude Mito), lysosomes and plasma membrane (Lyso/PM), endoplasmic reticulum (ER) and cytosol using western blot analysis. (b) CBD concentration in these fractions was quantified using $\mathrm{LC} / \mathrm{MS} / \mathrm{MS}$. (c) CBD concentration as detected in the various fractions of a continuous OptiPrep/sucrose membrane density gradient. CBD was mostly concentrated in fraction 6 and colocalized with the mitochondrial protein VDAC1. Data are representative of three independent experiments

In summary, in this study we have identified VDAC1 as a new molecular target for CBD. Our study suggests that CBD-induced cell death may occur through the inhibition of VDAC1 conductance and that this interaction may be responsible for the anticancer and immunosuppressive properties of CBD. However, we cannot rule out the possibility that the interaction of VDAC1 with CBD leads to cell death indirectly, for example by increasing the concentration of CBD in the mitochondria, thus leading to the increased formation of ROS and mitochondrial membrane permeability. We hypothesize that cancer and immune cells are more susceptible to CBD-induced cell death compared with other cell types due to their high proliferative rate, metabolic rate, and VDAC1 activity.

\section{Materials and Methods}

Reagents. GW9662 and cyclosporin A (Cys A) (dissolved in DMSO), WAY100635 (diluted in saline), Ruthenium red and N $\omega$-Nitro-L-arginine methyl ester (L-NAME) (diluted in water), and cholesterol (dissolved in sesame oil) were purchased from Sigma (St. Louis, MO, USA). Pertussis toxin (PTX), N-acetyl cysteine (NAC, diluted in water), and ZM241385 (dissolved in DMSO) were purchased from Tocris Bioscience (Bristol, UK). Cannabinoids (dissolved in either ethanol or DMSO) were obtained from NIDA. Other reagents were supplied with respective kits (see Flow cytometry section).

Cell culture. The BV-2 murine microglial cell line, originally generated by Professor E. Blasi (University of Perugia, Perugia, Italy), was kindly provided by
Professor EJ Choi from the Korea University (Seoul, Korea). Cells were grown under $5 \% \mathrm{CO}_{2}$ at $37^{\circ} \mathrm{C}$ in a growth medium composed of Dulbecco's modified Eagle's medium containing high glucose supplemented with $5 \%$ heat-inactivated fetal bovine serum, streptomycin $(100 \mu \mathrm{g} / \mathrm{ml})$, and penicillin $(100 \mathrm{U} / \mathrm{ml})($ Biological Industries Ltd., Kibbutz Beit Haemek, Israel).

siRNA and cell transfection. Scrambled and human specific hVDAC1siRNAs were synthesized by Dharmacon (Lafayette, CO). The following sequences were used:

si hVDAC1 sense: 238-5'-ACACUAGGCACCGAGAUUA3'-3'-256 and antisense: $5^{\prime}$-UAAUCUCGGUGCCUAGUGU-3'.

Scrambled sense: $5^{\prime}$-GCAAACAUCCCAGAGGUAU- $3^{\prime}$ and antisense: $5^{\prime}$ AUAC CUCUGGGAUGUUUGC3'.

U-87 cells were seeded ( 150000 cells/well) on six-well culture dishes to $30-50 \%$ confluence and transfected with $50 \mathrm{nM}$ siRNA hVDAC1 using JetPRIME reagent (PolyPlus transfection, Illkirch, France) according to the manufacturer's instructions.

Flow cytometry. Cell viability was measured by flow cytometry using propidium iodide (PI) staining. BV-2 cells $\left(9 \times 10^{5}\right.$ cells in $10 \mathrm{~cm}$ plates) were plated in growth medium. On the next day, growth medium was replaced with $5 \mathrm{ml}$ serum-free growth medium. The cells were pretreated with the indicated antagonists or vehicle, and then treated with CBD or ethanol (as vehicle at a final concentration of $0.1 \%$ ) for $2 \mathrm{~h}$. The cells were then scraped and spun down for $5 \mathrm{~min}$ at 2000 r.p.m. The pellets were washed twice with Dulbecco's PBS without $\mathrm{Ca}^{2+} / \mathrm{Mg}^{2+}$ and fixed in $70 \%$ ethanol at $-20{ }^{\circ} \mathrm{C}$ overnight. Cells were then washed in PBS and incubated with RNaseA $(0.2 \mathrm{mg} / \mathrm{ml})$ at $37^{\circ} \mathrm{C}$, PBS-rinsed and stained with PI ( $50 \mu \mathrm{g} / \mathrm{ml})$ for $15 \mathrm{~min}$ on ice. FACS analysis of 20000 cells (for each sample) was performed using a flow cytometer (Becton-Dickinson FACS Calibur, San Jose, CA, USA). The PI emission was detected in the FL2 channel 


\section{a} I $-10 \mathrm{mV}$

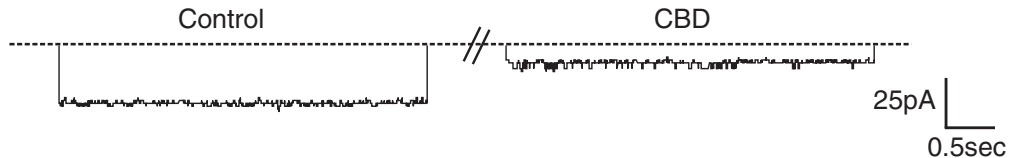

II $-60 \mathrm{mV}$
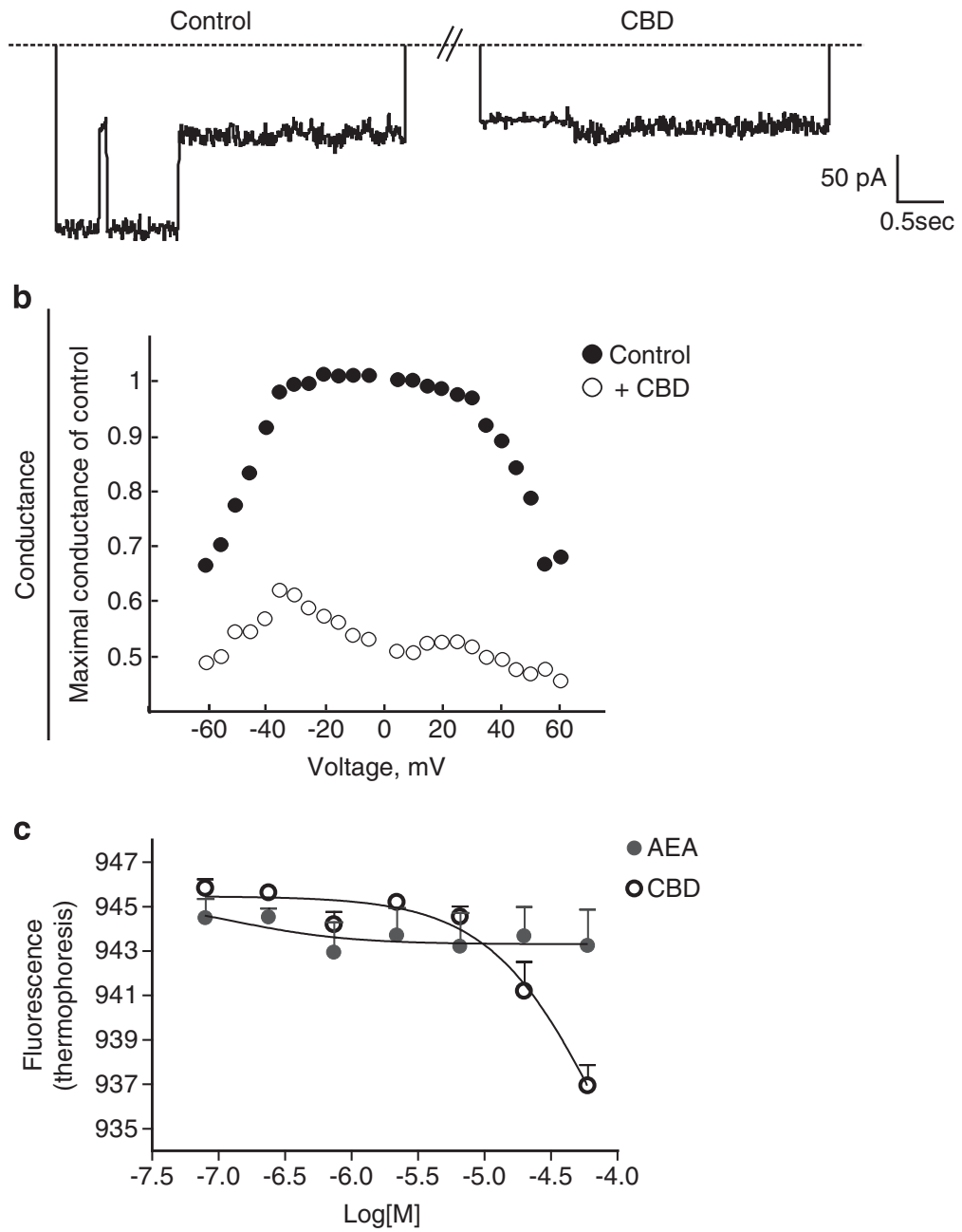

Figure $6 \mathrm{CBD}$ interacts with purified VDAC1 to decrease its channel conductance. (a) VDAC1 was reconstituted into PLB and channel currents in response to voltage steps, 0 to $-10 \mathrm{mV}(\mathrm{I})$ and 0 to $-60 \mathrm{mV}(\mathrm{II})$, were recorded before (control) and $15 \mathrm{~min}$ after the addition of $20 \mu \mathrm{M} \mathrm{CBD}$. A representative of three independent experiments is shown. The dashed lines indicate zero current. (b) The effect of CBD on VDAC1 conductance as a function of voltage, from $60 \mathrm{mV}$ to $-60 \mathrm{mV}$. The average steady-state conductance at any given voltage was normalized to the conductance at $10 \mathrm{mV}$. The recordings were taken before (control) and 15 min after the addition of CBD. (c) Thermophoretic analysis of CBD-VDAC1 interaction. The interaction between the fluorescently labeled purified VDAC1 and CBD (or the endocannabinoid AEA) was tested using thermophoresis (Laser power $80 \%$ ). VDAC1 and CBD (or AEA) were incubated for $30-60 \mathrm{~min}$ in PBS, with $2 \%$ ethanol as vehicle. The difference in fluorescence is plotted against CBD or AEA concentration. The data represent an average of three independent experiments (two of them in duplicates) for CBD, and two independent experiments in duplicates for AEA

using emission filter of $585 \mathrm{~nm}$. The data were analyzed using CellQuest software (BD, Oxford, UK). Apoptotic cells were defined as cells in the subG1 phase with hypodiploid DNA content.

Electron microscopy. BV-2 cells plated at $9 \times 10^{5}$ cells per $10 \mathrm{~cm}$ plate were treated with $10 \mu \mathrm{M}$ CBD or ethanol (as vehicle at a final concentration of $0.1 \%)$ for $6 \mathrm{~h}$ in the presence of $5 \%$ serum, or for $2 \mathrm{~h}$ in the absence of serum. Cells were fixed for $2 \mathrm{~h}$ in a fixative containing $3 \%$ paraformaldehyde, $2 \%$ glutaraldehyde, and $5 \mathrm{mM} \mathrm{CaCl}_{2}$ in $0.1 \mathrm{M}$ cacodylate buffer (pH 7.4). Cells were scraped, pelleted, and embedded in agar noble (in a final concentration of $1.7 \%$ ) and post-fixed with $1 \% \mathrm{OsO}_{4}, 0.5 \%$ potassium dichromate, and $0.5 \%$ potassium hexacyanoferrate in $0.1 \mathrm{M}$ cacodylate buffer. The pellet was stained en bloc with $2 \%$ aqueous uranyl acetate followed by ethanol dehydration and embedding in EMbed812 (Electron microscopic sciences, Fort Washington, PA, USA). Sections were cut using a diamond knife on a Leica Ultracut $E$ ultramicrotome and examined in a JEM 1200EXII transmission electron microscope (JEOL USA Inc., Peabody, MA, USA) equipped with an AMT XR-60 digital camera (Advanced Microscopy Techniques).

Single-cell calcium imaging. BV-2 cells were plated on poly--Llysinecoated glass coverslips. Twenty four hours later cells were loaded with $3 \mu \mathrm{M}$ Fura-2 AM in phenol red-free DMEM (containing $25 \mathrm{mM}$ HEPES) for $60 \mathrm{~min}$ at 
room temperature. Cells were then washed three times and mounted onto an inverted microscope (TS-100; Nikon, Tokyo, Japan). Test compounds were added to the cells after $60 \mathrm{~s}$ baseline recording. During recording, cells were alternately excited at 340 and $380 \mathrm{~nm}$ using a xenon arc illuminator by switching optical filters mounted in a computer-controlled Sutter wheel (Sutter Instrument Company, Novato, CA, USA). Excitation light was reflected from a dichroic mirror through a $\times 20$ plan fluor objective. Light emitted at an emission wavelength of $510 \mathrm{~nm}$ was projected onto a Cohu 4920 cooled charge-coupled device camera (Cohu, San Diego, CA, USA), and intracellular calcium concentrations were analyzed with the InCyt Im2 image acquisition and analysis software (Intracellular Imaging Inc., Cincinnati, $\mathrm{OH}$, USA) calibrated using a Fura-2 calibration kit (Invitrogen, Grand Island, NY, USA).

Imaging flow cytometry (IFC). Cells were stained as described below and 10000 events from each sample were collected and recorded using the ImageStreamX instrument. Samples were analyzed using IDEAS 4.0 software (Amnis Corp., Seattle, WA, USA). Cells were gated for single cells using the area and aspect ratio features, and for focused cells using the Gradient RMS feature, as previously described. ${ }^{58}$ For ROS detection, the Image-IT LIVE Green ROS Detection Kit was used according to the manufacturer's instructions (Molecular Probes Inc., Eugene, OR, USA). Briefly, cells were incubated with either CBD (0.1, $1,5,10 \mu \mathrm{M}$ ), ethanol (as vehicle at $0.1 \%$ final concentration), or $300 \mu \mathrm{M}$ tert-butyl hydroperoxide (TBHP) for $30 \mathrm{~min}$ in phenol red-free DMEM containing $25 \mathrm{mM}$ HEPES. Cells were then labeled with $25 \mu \mathrm{M}$ carboxy- $\mathrm{H}_{2}$ DCFDA $\left(2^{\prime}, 7^{\prime}\right.$-dichlorodihydrofluorescein diacetate) for $30 \mathrm{~min}$ at $37^{\circ} \mathrm{C}$ in the dark. Hoechst 33342 stain was added during the last 5 min of incubation. Cells were washed twice by spin down $(1000 \times g$ for $5 \mathrm{~min})$ and filtered through a $40-\mu \mathrm{m}$ mesh before IFC analysis. Data analysis was based on calculating median pixel intensity of gated cells (focused and single). To determine the changes in mitochondrial membrane potential the cells were incubated in phenol red-free DMEM containing $25 \mathrm{mM}$ HEPES and treated for $40 \mathrm{~min}$ at $37^{\circ} \mathrm{C}$ in the dark with CBD $(1,5,10,15 \mu \mathrm{M})$, ethanol, or $50 \mu \mathrm{M}$ carbonyl cyanide 3-chlorophenyl hydrazone (CCCP). The dye tetramethylrhodamine-methyl ester (TMRM) at $250 \mathrm{nM}$ (Santa Cruz Biotechnology, Dallas, TX, USA) was added for the last 20 min of incubation. Cells were washed twice by spin down and filtered through a $40-\mu \mathrm{m}$ mesh before IFC analysis. Image data analysis was based on calculating bright detailed intensity (BDI), defined as the intensity of localized bright spots within the masked area in the image. BDI computes the intensity of bright spots that are three pixels in radius or less. The local background around the spots is removed before the intensity computation.

Antibodies. Coatomer subunit $\beta$ ( $\beta-C O P)$ mouse monoclonal antibody (1:1000; Sigma-Aldrich, St. Louis, MO, USA, \#6160), detecting a 110-kDA protein was used with an HRP-goat anti-mouse IgG (1:10000) secondary Ab. VDAC1 rabbit polyclonal antibody (1:1000; Abcam, ab-15895) detecting a 34-kDa protein was used with an HRP-goat anti-rabbit lgG (1:10000). Mouse monoclonal antibody against $\beta$-actin (1:10 000; Santa Cruz Biotechnology) detecting a 45-KDa protein was used with an HRP-goat anti-mouse IgG (1:10 000) secondary Ab. Rat monoclonal anti LAMP1 (1:1000; Developmental studies hybridoma bank, $\mathrm{NIH}$, 1D4B) detecting a 110-KDa protein was used with an HRP-rat anti-mouse IgG (1:10000) secondary Ab.

Western blot analysis. Membrane components present in fractions were lysed by the addition of SDS, NP-40 and Triton X-100 to the final concentrations of $0.5,1$, and $1 \%$, respectively. Samples were incubated on ice for $30 \mathrm{~min}$. Laemmli loading buffer was added to the samples and they were denatured for $3 \mathrm{~min}$ at $70^{\circ} \mathrm{C}$. Samples were separated by $10 \%$ SDS-PAGE and transferred to nitrocellulose membranes. The membranes were incubated in blocking buffer consisting of $10 \mathrm{mM}$ Tris- $\mathrm{HCl}(\mathrm{pH} 7.5), 150 \mathrm{mM} \mathrm{NaCl}$, and $0.1 \%$ Tween-20 (TBST) with $5 \%$ w/v skim milk. The membranes were washed with TBST for five times and incubated with primary antibody in $3 \%$ BSA for $1 \mathrm{~h}$ at room temperature or overnight at $4{ }^{\circ} \mathrm{C}$. The membranes were washed five times with TBST, and then incubated for $1 \mathrm{~h}$ with the appropriate secondary antibodies. The blots were washed five times and processed using chemiluminescence detection.

Cellular organelle fractionation. Cellular fractions of crude mitochondria, lysosomes + plasma membrane, ER, and cytosol were isolated according to Wieckowski et al. ${ }^{40}$ Briefly, $20 \times 150 \mathrm{~mm}$ cell culture dishes (per condition) were incubated with CBD (10 $\mu \mathrm{M}, 3 \mathrm{~h}, 5 \%$ serum). Medium was removed and cells were washed twice with calcium- and magnesium-free PBS. Cells were scraped in DMEM and collected into $50 \mathrm{ml}$ tubes. Cells were centrifuged at $600 \times g$ for $5 \mathrm{~min}$ a $4{ }^{\circ} \mathrm{C}$, resuspended in a small volume of PBS and combined. Centrifugation was repeated $\left(600 \times g\right.$ for $5 \mathrm{~min}$ at $\left.4^{\circ} \mathrm{C}\right)$ and cell pellet was resuspended in $20 \mathrm{ml}$ icecold $\mathrm{IB}_{\text {cells }}{ }^{-1}$ buffer ( $225 \mathrm{mM}$ mannitol, $75 \mathrm{mM}$ sucrose, $0.1 \mathrm{mM}$ EGTA, and $30 \mathrm{mM}$ Tris- $\mathrm{HCl}, \mathrm{pH}$ 7.4). Cells were then lysed by passage through a $27 \mathrm{~g} \mathrm{X} 3^{\prime \prime}$ needle for 20 times and centrifuged at $600 \times g$ for $5 \mathrm{~min}$ at $4^{\circ} \mathrm{C}$. Supernatant was collected and pellet was discarded. Supernatant was centrifuged again at $600 \times g$ for $5 \mathrm{~min}$ at $4^{\circ} \mathrm{C}$, collected, and centrifuged again at $7000 \times \mathrm{g}$ for $10 \mathrm{~min}$ at $4{ }^{\circ} \mathrm{C}$. The supernatant (S1) was collected and saved at $4{ }^{\circ} \mathrm{C}$ for further separation of cytosolic, lysosomal, and ER fractions. The pellet containing the crude mitochondria was resuspended in $\mathrm{IB}_{\text {cells }}-2$ buffer $(225 \mathrm{mM}$ mannitol, $75 \mathrm{mM}$ sucrose, and $30 \mathrm{mM}$ Tris- $\mathrm{HCl}, \mathrm{pH} 7.4$ ) and centrifuged at $7000 \times g$ for $10 \mathrm{~min}$ at $4{ }^{\circ} \mathrm{C}$. The supernatant was discarded and the pellet was resuspended in $\mathrm{IB}_{\text {cells }}-2$ buffer and centrifuged at $7000 \times g$ for $10 \mathrm{~min}$ at $4{ }^{\circ} \mathrm{C}$. The supernatant was discarded and the pellet was resuspended in $\mathrm{IB}_{\text {cells }}{ }^{-2}$ buffer and centrifuged at $10000 \times g$ for $10 \mathrm{~min}$ at $4{ }^{\circ} \mathrm{C}$. The pellet containing crude mitochondria was resuspended in $2 \mathrm{ml}$ MRB buffer ( $250 \mathrm{mM}$ mannitol, $5 \mathrm{mM}$ HEPES ( $\mathrm{pH} 7.4$ ), and $0.5 \mathrm{mM}$ EGTA), and $0.4 \mathrm{ml}$ of it was frozen in $-20^{\circ} \mathrm{C}$ for lipid and protein analysis. In order to separate additional organelles, $\mathrm{S} 1$ supernatant was centrifuged at $20000 \times \mathrm{g}$ for $30 \mathrm{~min}$ at $4^{\circ} \mathrm{C}$. The pellet containing the lysosomal + plasma membrane fraction was frozen at $-20^{\circ} \mathrm{C}$ for lipid and protein analysis. The supernatant was further centrifuged at $100000 \times g$ for $1 \mathrm{~h}$ at $4{ }^{\circ} \mathrm{C}$, yielding an ER fraction (pellet) and a cytosolic fraction (supernatant), which were frozen at $-20^{\circ} \mathrm{C}$ for lipid and protein analysis.

Cell membrane fractionation. Procedures for membrane fractionation were adapted from the method of Macdonald and Pike. ${ }^{41}$ Briefly, cells were plated $24 \mathrm{~h}$ before the experiment. On the day of the experiment, cells from four $150 \mathrm{~mm}$ plates (for each experimental condition) were washed once with PBS and scraped into a total of $25 \mathrm{ml}$ of $4^{\circ} \mathrm{C}$ base buffer ( $20 \mathrm{mM}$ Tris- $\mathrm{HCl}, 250 \mathrm{mM}$ sucrose, $\mathrm{pH} 7.8$ ) containing $1 \mathrm{mM}$ calcium chloride and $1 \mathrm{mM}$ magnesium chloride. Cells were centrifuged in a polystyrene tube at $200 \times g$ for $7 \mathrm{~min}$ at $4^{\circ} \mathrm{C}$. The pellet was resuspended in $1.0 \mathrm{ml}$ of base buffer containing calcium chloride, magnesium chloride, and protease inhibitor cocktail (Sigma Aldrich, cat \# P8340). Cells were then lysed by passage through a $27 \mathrm{~g} \mathrm{X} 3^{\prime \prime}$ needle for 20 times and centrifuged at $1000 \times g$ for $10 \mathrm{~min}$ at $4{ }^{\circ} \mathrm{C}$. The post-nuclear supernatant was transferred to a new tube. The pellet was resuspended in base buffer containing calcium chloride, magnesium chloride, and protease inhibitors, and the procedure was repeated. The two post-nuclear supernatants were combined and 50\% OptiPrep (Axis Shield, Dundee, UK) in base buffer was added to give a $4 \mathrm{ml}$ solution of $25 \%$ OptiPrep. This solution was laid under an $8 \mathrm{ml}$ continuous density gradient of $20 \%-0 \%$ OptiPrep in base buffer in Ultra-Clear $(14 \times 89 \mathrm{~mm})$ centrifuge tubes. The gradient was centrifuged using an SW-41 swinging bucket rotor (Beckman Coulter, Fullerton, CA, USA) for $90 \mathrm{~min}$ at $52000 \times \mathrm{g}$ at $4{ }^{\circ} \mathrm{C}$. Fractions of $0.75 \mathrm{ml}$ were collected from each gradient.

Mass spectrometry. The quantity of $\mathrm{CBD}$ in each of the fractions was measured as previously described. ${ }^{33}$ Briefly, fractions were diluted with $100 \%$ HPLC grade methanol. Each sample was spiked with $200 \mathrm{pmol}$ of d8-Narachidonoyl glycine and HPLC grade water was added to make a $75 \%$ aqueous solution. These $75 \%$, aqueous solutions were loaded onto $500 \mathrm{mg} \mathrm{C18}$ Bond Elut solid phase extraction columns (Agilent, Lake Forest, CA, USA) that were preconditioned with $5 \mathrm{ml}$ HPLC grade methanol followed by $2.5 \mathrm{ml}$ HPLC water. The columns were then washed with $20 \mathrm{ml}$ water. Sequential elutions $(1.5 \mathrm{ml}$ each of $60,75,85$, and $100 \%$ methanol) were collected for mass spectrometric analysis. An aliquot of each of the eluates was loaded using a Shimadzu 20AC autosampler (Shimadzu, Wilmington, DE, USA) onto a reversed-phase Zorbax $2.1 \times 50 \mathrm{~mm}$ $\mathrm{C} 18$ column maintained at $40^{\circ} \mathrm{C}$. HPLC gradient formation at a flow rate of $200 \mu \mathrm{l} /$ min was achieved by a system comprising a Shimadzu controller and two Shimadzu LC10ADvp pumps. Lipid levels in the samples were analyzed in multiple reaction monitoring (MRM) mode on a triple quadrupole mass spectrometer, API 3000 (Applied Biosystems/MDS SCIEX, Foster city, CA, USA), with electrospray ionization. Methods for lipid analysis were optimized by flow injection of lipid standards. All quantitation calculations were based on calibration curves using the CBD synthetic standard. The following molecular ion and fragment ion pair was used to quantify CBD in MRM mode: CBD $315.2 \rightarrow 193.1$ 
VDAC1 purification, channel reconstitution and recordings. VDAC1 from sheep liver mitochondria was solubilized with lauryl-dimethylamineoxide (LDAO) and purified using hydroxyapatite: celite resin as previously described. ${ }^{59}$ VDAC1 channel was reconstituted into a planar lipid bilayer (PLB) prepared from soybean asolectin dissolved in $n$-decane $(30 \mathrm{mg} / \mathrm{ml})$. Purified VDAC1 was added to the cis chamber containing $0.5 \mathrm{M} \mathrm{NaCl}$ and $10 \mathrm{mM}$ HEPES, $\mathrm{pH}$ 7.4. After one or more channels were inserted into the PLB, excess protein was removed by prefusing the cis chamber to prevent further channel incorporation. Currents were recorded by voltage-clamping using a Bilayer Clamp BC-525B amplifier (Warner Instruments, Hamden, CT, USA). Current was measured with respect to the trans side of the membrane (serving as ground). The current was digitized on-line using a Digidata 1200 interface board and pCLAMP 10.2 software (Axon Instruments, Union City, CA, USA).

Microscale thermophoresis. Microscale thermophoresis (MST) reflects the directed movement of particles in a microscopic temperature gradient, and enables quantitative analysis of molecular interactions in solution at microliter scale. MST analysis was performed using a NanoTemper Monolith NT.115 apparatus, as recently described. ${ }^{60}$ Briefly, purified rat liver mitochondrial VDAC1 was fluorescently labeled using the NanoTemper Protein-labeling kit Blue (Nano Temper Technologies, Munich, Germany). A concentration of $133 \mathrm{nM}$ VDAC1 was incubated for $30-60 \mathrm{~min}$ at room temperature in the dark with different concentrations of CBD (in PBS containing 2\% ethanol as vehicle). The samples (3-5 $\mu$ l) were loaded into standard glass capillaries (Monolith NT Capillaries) and thermophoresis analysis was performed (LED 40\%, IR laser 80\%). Dissociation constants were calculated using the NanoTemper 1.2.206 analysis program.

Statistical analysis. SPSS was used for statistical analysis. Results were expressed as the mean \pm S.E.M. and analyzed by one-way analysis of variance (ANOVA) followed by Bonferroni or LSD post hoc tests $(P<0.05$ has been considered as significant). Dose-response curves were calculated and plotted using GraphPad prism software (La Jolla, CA, USA).

\section{Conflict of Interest}

The authors declare no conflict of interest.

Acknowledgements. This work was supported by the Dr. Miriam and Sheldon $G$ Adelson Medical Research Foundation. AJ is supported by the Israeli Ministry for Absorption in Science. We thank Dr. Or Golan and Professor Asher Shainberg from The Cancer Research Center, Bar Ilan University, Ramat Gan, Israel, for the preliminary experiments on mitochondrial membrane potential.

1. Russo E, Guy GW. A tale of two cannabinoids: the therapeutic rationale for combining tetrahydrocannabinol and cannabidiol. Med Hypothes 2006; 66: 234-246.

2. Weiss L, Zeira M, Reich S, Slavin S, Raz I, Mechoulam R et al. Cannabidiol arrests onset of autoimmune diabetes in NOD mice. Neuropharmacology 2008; 54: 244-249.

3. McAllister SD, Murase R, Christian RT, Lau D, Zielinski AJ, Allison J et al. Pathways mediating the effects of cannabidiol on the reduction of breast cancer cell proliferation, invasion, and metastasis. Breast Cancer Res Treat 2011; 129: 37-47.

4. Malfait AM, Gallily R, Sumariwalla PF, Malik AS, Andreakos E, Mechoulam R et al. The nonpsychoactive cannabis constituent cannabidiol is an oral anti-arthritic therapeutic in murine collagen-induced arthritis. Proc Natl Acad Sci USA 2000; 97: 9561-9566.

5. Kozela E, Lev N, Kaushansky N, Eilam R, Rimmerman N, Levy R et al. Cannabidiol inhibits pathogenic $\mathrm{T}$ cells, decreases spinal microglial activation and ameliorates multiple sclerosis-like disease in C57BL/6 mice. Br J Pharmacol 2011; 163: $1507-1519$.

6. Moreira FA, Aguiar DC, Guimaraes FS. Anxiolytic-like effect of cannabidiol in the rat Vogel conflict test. Progress Neuro-psychopharmacol Biol Psychiatr 2006; 30: 1466-1471.

7. Rock EM, Bolognini D, Limebeer CL, Cascio MG, Anavi-Goffer S, Fletcher PJ et al. Cannabidiol, a non-psychotropic component of cannabis, attenuates vomiting and nausealike behaviour via indirect agonism of $5-\mathrm{HT}(1 \mathrm{~A})$ somatodendritic autoreceptors in the dorsal raphe nucleus. Br J Pharmacol 2012; 165: 2620-2634.

8. Fernandez-Ruiz J, Sagredo O, Pazos MR, Garcia C, Pertwee R, Mechoulam R et al. Cannabidiol for neurodegenerative disorders: important new clinical applications for this phytocannabinoid? Br J Clin Pharmacol 2012; 75: 323-333.

9. Ligresti A, Moriello AS, Starowicz K, Matias I, Pisanti S, De Petrocellis L et al. Antitumor activity of plant cannabinoids with emphasis on the effect of cannabidiol on human breast carcinoma. J Pharmacol Exp Ther 2006; 318: 1375-1387.
10. Leweke FM, Piomelli D, Pahlisch F, Muhl D, Gerth CW, Hoyer C et al. Cannabidiol enhances anandamide signaling and alleviates psychotic symptoms of schizophrenia. Transl Psychiatr 2012; 2: e94.

11. Rimmerman N, Kozela E, Levy R, Vogel Z, Juknat A. Cannabinoid signaling through non-CB1, non-CB2 GPCR targets in microglia. In Abood ME, Sorensen RG, Stella N (eds) Actions at Non-CB1/CB2 Cannabinoid Receptors. Springer: New York, 2013. pp 143-171.

12. Carrier EJ, Auchampach JA, Hillard CJ. Inhibition of an equilibrative nucleoside transporter by cannabidiol: a mechanism of cannabinoid immunosuppression. Proc Nat/ Acad Sci USA 2006; 103: 7895-7900.

13. De Petrocellis L, Ligresti A, Moriello AS, Allara M, Bisogno T, Petrosino S et al. Effects of cannabinoids and cannabinoid-enriched Cannabis extracts on TRP channels and endocannabinoid metabolic enzymes. Br J Pharmacol 2011; 163: 1479-1494.

14. O'Sullivan SE, Kendall DA. Cannabinoid activation of peroxisome proliferator-activated receptors: potential for modulation of inflammatory disease. Immunobiology 2010; 215: 611-616.

15. Ryan D, Drysdale AJ, Lafourcade C, Pertwee RG, Platt B. Cannabidiol targets mitochondria to regulate intracellular Ca2 + levels. J Neurosci 2009; 29: 2053-2063.

16. Drysdale AJ, Ryan D, Pertwee RG, Platt B. Cannabidiol-induced intracellular $\mathrm{Ca} 2+$ elevations in hippocampal cells. Neuropharmacology 2006; 50: 621-631.

17. Massi P, Vaccani A, Bianchessi S, Costa B, Macchi P, Parolaro D. The non-psychoactive cannabidiol triggers caspase activation and oxidative stress in human glioma cells. Cell Mol Life Sci 2006; 63: 2057-2066.

18. Castillo A, Tolon MR, Fernandez-Ruiz J, Romero J, Martinez-Orgado J. The neuroprotective effect of cannabidiol in an in vitro model of newborn hypoxic-ischemic brain damage in mice is mediated by $\mathrm{CB}(2)$ and adenosine receptors. Neurobiol Dis 2010; 37: 434-440

19. Shrivastava A, Kuzontkoski PM, Groopman JE, Prasad A. Cannabidiol induces programmed cell death in breast cancer cells by coordinating the cross-talk between apoptosis and autophagy. Mol Cancer Ther 2011; 10: 1161-1172.

20. Gallily R, Even-Chena T, Katzavian G, Lehmann D, Dagan A, Mechoulam R. Gamma-irradiation enhances apoptosis induced by cannabidiol, a non-psychotropic cannabinoid, in cultured HL-60 myeloblastic leukemia cells. Leuk Lymph 2003; 44: 1767-1773.

21. Vaccani A, Massi P, Colombo A, Rubino T, Parolaro D. Cannabidiol inhibits human glioma cell migration through a cannabinoid receptor-independent mechanism. Br J Pharmacol 2005; 144: 1032-1036.

22. McKallip RJ, Jia W, Schlomer J, Warren JW, Nagarkatti PS, Nagarkatti M. Cannabidiolinduced apoptosis in human leukemia cells: A novel role of cannabidiol in the regulation of p22phox and Nox4 expression. Mol Pharmacol 2006; 70: 897-908.

23. Lee CY, Wey SP, Liao MH, Hsu WL, Wu HY, Jan TR. A comparative study on cannabidiolinduced apoptosis in murine thymocytes and EL-4 thymoma cells. Int Immunopharmacol 2008; 8: 732-740

24. Wu HY, Chu RM, Wang CC, Lee CY, Lin SH, Jan TR. Cannabidiol-induced apoptosis in primary lymphocytes is associated with oxidative stress-dependent activation of caspase-8. Toxicol Appl Pharmacol 2008; 226: 260-270.

25. Wu HY, Chang AC, Wang CC, Kuo FH, Lee CY, Liu DZ et al. Cannabidiol induced a contrasting pro-apoptotic effect between freshly isolated and precultured human monocytes. Toxicol Appl Pharmacol 2010; 246: 141-147.

26. Raz A, Goldman R. Effect of hashish compounds on mouse peritoneal macrophages. Lab Invest 1976; 34: 69-76.

27. Rimmerman N, Juknat A, Kozela E, Levy R, Bradshaw HB, Vogel Z. The non-psychoactive plant cannabinoid, cannabidiol affects cholesterol metabolism-related genes in microglial cells. Cell Mol Neurobiol 2011; 31: 921-930.

28. Wu HY, Goble K, Mecha M, Wang CC, Huang CH, Guaza $\mathrm{C}$ et al. Cannabidiol-induced apoptosis in murine microglial cells through lipid reft. Glia 2012; 60: 1182-1190.

29. Kozela E, Pietr M, Juknat A, Rimmerman N, Levy R, Vogel Z. Cannabinoids Delta(9)tetrahydrocannabinol and cannabidiol differentially inhibit the lipopolysaccharide-activated NF-kappaB and interferon-beta/STAT proinflammatory pathways in BV-2 microglial cells. J Biol Chem 2010; 285: 1616-1626.

30. Juknat A, Pietr M, Kozela E, Rimmerman N, Levy R, Coppola G et al. Differential transcriptional profiles mediated by exposure to the cannabinoids cannabidiol and Delta9-tetrahydrocannabinol in BV-2 microglial cells. Br J Pharmacol 2012; 165 : 2512-2528.

31. Juknat A, Rimmerman N, Levy R, Vogel Z, Kozela E. Cannabidiol affects the expression of genes involved in zinc homeostasis in BV-2 microglial cells. Neurochem Int 2012; 61: 923-930.

32. Juknat A, Pietr M, Kozela E, Rimmerman N, Levy R, Gao F et al. Microarry and pathway analysis reveal distinct mechanisms underlying cannabinoid-mediated modulation of LPSinduced activation of BV-2 microglial cells. Plos One 2013; 10: 1371.

33. Rimmerman N, Bradshaw HB, Kozela E, Levy R, Juknat A, Vogel Z. Compartmentalization of endocannabinoids into lipid rafts in a microglial cell line devoid of caveolin-1. Br J Pharmacol 2012; 165: 2436-2449.

34. Shoshan-Barmatz V, Ben-Hail D. VDAC, a multi-functional mitochondrial protein as a pharmacological target. Mitochondrion 2011; 12: 24-34.

35. Shoshan-Barmatz V, De Pinto V, Zweckstetter M, Raviv Z, Keinan N, Arbel N. VDAC, a multi-functional mitochondrial protein regulating cell life and death. Mol Aspect Med 2010; 31: $227-285$ 
36. Shoshan-Barmatz V, Mizrachi D. VDAC1: from structure to cancer therapy. Front Oncol 2012; 2: 164 PMID 20471992.

37. Ramer R, Heinemann K, Merkord J, Rohde H, Salamon A, Linnebacher M et al. COX-2 and PPAR-gamma confer cannabidiol-induced apoptosis of human lung cancer cells. Mol Cancer Ther 2012; 12: 69-82.

38. Ribeiro A, Ferraz-de-Paula V, Pinheiro ML, Vitoretti LB, Mariano-Souza DP, Quinteiro-Filho WM et al. Cannabidiol, a non-psychotropic plant-derived cannabinoid, decreases inflammation in a murine model of acute lung injury: role for the adenosine A(2A) receptor. Eur J Pharmacol 2012; 678: 78-85.

39. Mato S, Victoria Sanchez-Gomez M, Matute C. Cannabidiol induces intracellular calcium elevation and cytotoxicity in oligodendrocytes. Glia 2010; 58: 1739-1747.

40. Wieckowski MR, Giorgi C, Lebiedzinska M, Duszynski J, Pinton P. Isolation of mitochondria-associated membranes and mitochondria from animal tissues and cells. Nat Protoc 2009; 4: 1582-1590.

41. Macdonald JL, Pike LJ. A simplified method for the preparation of detergent-free lipid rafts. J Lipid Res 2005; 46: 1061-1067.

42. Rimmerman N, Hughes HV, Bradshaw HB, Pazos MX, Mackie $\mathrm{K}$, Prieto AL et at. Compartmentalization of endocannabinoids into lipid rafts in a dorsal root ganglion cell line. Br J Pharmacol 2008; 153: 380-389.

43. Siemen $\mathrm{D}$, Ziemer $\mathrm{M}$. What is the nature of the mitochondrial permeability transition pore and what is it not? IUBMB Life 2013; 65: 255-262.

44. Shoshan-Barmatz V, Gincel D. The voltage-dependent anion channel: characterization, modulation, and role in mitochondrial function in cell life and death. Cell Biochem Biophys 2003; 39: 279-292.

45. Tsujimoto Y, Shimizu S. Role of the mitochondrial membrane permeability transition in cell death. Apoptosis 2007; 12: 835-840.

46. Vander Heiden MG, Chandel NS, Li XX, Schumacker PT, Colombini M, Thompson CB. Outer mitochondrial membrane permeability can regulate coupled respiration and cell survival. Proc Natl Acad Sci USA 2000; 97: 4666-4671.

47. Abu-Hamad S, Sivan S, Shoshan-Barmatz V. The expression level of the voltagedependent anion channel controls life and death of the cell. Proc Natl Acad Sci USA 2006 103: $5787-5792$.

48. Popp B, Schmid A, Benz R. Role of sterols in the functional reconstitution of water-soluble mitochondrial porins from different organisms. Biochemistry 1995; 34: 3352-3361.

49. Hiller S, Garces RG, Malia TJ, Orekhov VY, Colombini M, Wagner G. Solution structure of the integral human membrane protein VDAC-1 in detergent micelles. Science 2008; 321 1206-1210.
50. Campbell AM, Chan SH. Mitochondrial membrane cholesterol, the voltage dependent anion channel (VDAC), and the Warburg effect. J Bioenerget Biomem 2008; 40: 193-197.

51. Rone MB, Midzak AS, Issop L, Rammouz G, Jagannathan S, Fan J et al. Identification of a dynamic mitochondrial protein complex driving cholesterol import, trafficking, and metabolism to steroid hormones. Mol Endocrinol 2009; 26: 1868-1882.

52. Gincel D, Zaid H, Shoshan-Barmatz V. Calcium binding and translocation by the voltage-dependent anion channel: a possible regulatory mechanism in mitochondrial function. Biochem J 2001; 358: 147-155.

53. Rapizzi E, Pinton P, Szabadkai G, Wieckowski MR, Vandecasteele G, Baird G et al. Recombinant expression of the voltage-dependent anion channel enhances the transfer of $\mathrm{Ca} 2+$ microdomains to mitochondria. J Cell Biol 2002; 159: 613-624.

54. Tan W, Colombini M. VDAC closure increases calcium ion flux. Biochim Biophys Acta 2007; 1768: 2510-2515.

55. Zaid H, Abu-Hamad S, Israelson A, Nathan I, Shoshan-Barmatz V. The voltage-dependent anion channel-1 modulates apoptotic cell death. Cell Death Differ 2005; 12: 751-760.

56. Saba R, Gushue S, Huzarewich RL, Manquiat K, Medina S, Robertson C et al. MicroRNA $146 \mathrm{a}(\mathrm{miR}-146 \mathrm{a})$ is over-expressed during prion disease and modulates the innate immune response and the microglial activation state. PloS One 2012; 7: e30832.

57. Massi P, Vaccani A, Ceruti S, Colombo A, Abbracchio MP, Parolaro D. Antitumor effects of cannabidiol, a nonpsychoactive cannabinoid, on human glioma cell lines. J Pharmacol Exp Ther 2004; 308: 838-845.

58. George TC, Fanning SL, Fitzgerald-Bocarsly P, Medeiros RB, Highfill S, Shimizu Y et al. Quantitative measurement of nuclear translocation events using similarity analysis of multispectral cellular images obtained in flow. J Immunol Methods 2006; 311: 117-129.

59. Arbel N, Ben-Hail D, Shoshan-Barmatz V. Mediation of the antiapoptotic activity of Bcl-xL protein upon interaction with VDAC1 protein. J Biol Chem 2012; 287: 23152-23161.

60. Wienken CJ, Baaske P, Rothbauer U, Braun D, Duhr S. Protein-binding assays in biological liquids using microscale thermophoresis. Nat Commun 2010; 1: 100.

(i) $(\Theta)$ Cell Death and Disease is an open-access journa published by Nature Publishing Group. This work is licensed under a Creative Commons Attribution-NonCommercialNoDerivs 3.0 Unported License. To view a copy of this license, visit http://creativecommons.org/licenses/by-nc-nd/3.0/ 